

\title{
Espacialidades de Hombres Trans Youtubers: Acercamiento a sus Condiciones en la Pandemia del Covid-19
}

\section{Espacialidades de Homens Trans Youtubers: Abordagem de suas Condições na Pandemia Covid-19}

\author{
Spatialities of Transmen Youtubers: An Approach to their Conditions in the \\ Covid-19 Pandemic
}

\section{Resumen}

Los hombres trans en YouTube están produciendo la memoria corporal de sus tránsitos: sus experiencias emocionales, físicas, familiares, sociales y sexuales de cómo se va siendo trans. Por ello, me pregunto ¿de qué manera los videos de YouTube van configurando otros espacios en Internet? ¿será Internet una plataforma de expansión sobre las posibilidades de habitar el cuerpo-espacio trans? Partiendo de los enfoques relacionales del espacio y las geografías queer, se realizó una etnografía móvil que posibilitara navegar tanto en los espacios de la pantalla de Internet como en los encuentros presenciales, con el fin de señalar las posibilidades socioespaciales que se producen en Internet.

Palavras-Chave: Hombres Trans; Internet; YouTube; Tránsito de Género.

\section{Resumo}

Homens trans no YouTube estão produzindo a memória corporal de seus trânsitos: suas experiências emocionais, físicas, familiares, sociais e sexuais de como se tornar um trans. Portanto, eu me pergunto como os vídeos do YouTube estão moldando outros espaços na Internet? A Internet será uma plataforma de expansão das possibilidades de habitar o espaço trans-corporal? Partindo das abordagens relacionais ao espaço e às geografias queer, foi realizada uma etnografia móvel que possibilitou navegar tanto nos espaços da tela da Internet quanto nos encontros presenciais, a fim de apontar as possibilidades socioespaciais que ocorrem na Internet.

Palabras-Clave: Homens Trans; Internet; YouTube; Trânsito de Gênero.

\begin{abstract}
Trans men on YouTube are producing the body memory of their transits: their emotional, physical, family, social and sexual experiences of how to become trans. Therefore, I wonder how YouTube videos are shaping other spaces on the Internet? Will the Internet be an expansion platform on the possibilities of inhabiting the trans body-space? Starting from the relational approaches to space and queer geographies, a mobile ethnography was carried out that made it possible to navigate both on the Internet screen spaces and in face-to-face encounters, in order to point out the socio-spatial possibilities that occur on the Internet.
\end{abstract}

Keywords: Trans Men; Internet; YouTube; Gender Transition. 


\section{Introducción}

Este artículo emerge como producto de la tesis de Maestría en Estudios Socioespaciales, en donde analicé cómo la producción de videos en YouTube por hombres trans, está creando otros espacios para existir. Partiendo de los enfoques relacionales del espacio donde se reconoce que los espacios no están esperando un significado, sino que tienen un papel activo en la producción de prácticas, discursos, recuerdos, es decir en la producción de relaciones socioespaciales, como a la vez las personas y las materialidades dan forma, delimitan, engendran determinados tiempos y espacios (KITCHIN \& DODGE, 2011). De otro modo, las geografías queer nos permitirán dar cuenta de la movilidad e inestabilidad de las identidades en el marco de la Cisheteronormatividad, entendida como la confluencia de sistemas de poder que privilegian los cuerpos cis $^{1}$ sobre los trans, y la heterosexualidad como forma de relacionamiento válido y posible entre los cuerpos.

Este artículo estará compuesto por cuatro partes, primero una presentación del proceso metodológico, de cómo expandir la práctica etnográfica más allá de los lugares limitados y definidos en las bases clásicas de la antropología, y por ello retomo el concepto de "etnografía móvil" de Ana P. Gutiérrez (2012); segundo, explicar el contexto en el cual emergen varios hombres trans en YouTube en Colombia; tercero, la espacialidad del código FTM como productor de espacio y finalmente, cómo los cuerpos trans están viviendo la pandemia de la Covid-19 y la arquitectura de sus canales produce espacios de encuentro, interpelación y denuncia política frente a sus vulneraciones.

\section{Conectando con los Youtubers}

La reflexión metodológica de hacer investigación en espacios de la internet, implica cuestionar, no solo el lugar desde dónde se hace la investigación, como las feministas nos han señalado, sino también la postura ética ante la posibilidad de no ser visto, y disponer de un amplio abanico de datos para las investigaciones en la Internet. Ante este panorama, mi apuesta académica y política pasó del encubrimiento al diálogo y al intercambio de posturas frente a la investigación. Para ello, retomé la propuesta metodológica de la antropóloga Ana P. Gutiérrez (2012) en su investigación sobre travestis, que denominó "etnografía móvil", la cual plantea la necesidad de explorar, tanto los espacios "virtuales" como los encuentros presenciales. Los primeros los llamaremos “espacios de la pantalla de la Internet" (KELLERMAN, 2016) entendidos como espacios no estables, que pueden desaparecer por comandos o por modificaciones que hagan sus usuarios. Los presenciales se llevaron a cabo con con tres hombres trans, dos colombianos Hugo y Martin y uno mexicano, Carlos. Del clic para ver sus vídeos, llegué a las ciudades de Bogotá, Armenia y Ciudad de México, respectivamente, para conocernos, explicarles cuáles eran mis intenciones académicas y políticas frente a la investigación, y poder crear redes entre nosotrxs ${ }^{2}$.

1 Cis es un prefijo que significa "de este lado" y que se refiere a las personas que se reconocen en el género y en el sexo asignado al nacer. 


\section{El boom de hombres trans en YouTube}

En el año 2016 en Colombia, el discurso de la "ideología de género" conectó dos procesos que estaban ocurriendo de manera simultánea, la implementación de las cartillas de educación no homolesbotransfóbicas en las instituciones educativas, ordenado por la Corte Constitucional y el Acuerdo de Paz entre el gobierno de Juan Manuel Santos y las Fuerzas Armadas Revolucionarias de Colombia - Ejército del Pueblo (Farc-EP) ${ }^{3}$. El despliegue de la "ideología de género" se presentó como una amenaza a la democracia, manifestado a través de un pánico sexual por la posibilidad de "homosexualizar a sus hijos" (RODRÍGUEZ, 2017) y borrar la diferencia sexual que instituye el régimen heterosexual en la constitución política de Colombia (CURIEL, 2013).

Para el 2017, mientras pasaba el bus transfóbico por América Latina, hubo un "boom", en mis términos, de hombres trans youtubers colombianos que activaron el vídeo en sus celulares y dijeron "soy trans y quiero contarles un poco de mí". Esto fue posible identificarlo porque en el lenguaje de la Internet y especialmente de YouTube, se ha constituido un código, es decir unas letras que al ser buscadas por los algoritmos arrojan determinados datos, por ejemplo, la sigla FTM Colombia (Female To Male, en inglés), como sucede con los otros países FTM México, FTM Argentina, etc. En medio de los discursos de odio, de las violencias materiales y simbólicas hacia la población 2 Utilizo la $\mathrm{x}$ para aludir a quienes nos reconocemos dentro de lo masculino, femenino o en
ninguno de los dos.

3 Ahora denominada Fuerza Alternativa Revolucionaria del Común (Farc), luego de su constitución como partido político legal. 
LGBTI en Colombia (PRADA, N. et al. 2016) como en varios países de América Latina, la producción de vídeos en YouTube emergía de una necesidad y una ausencia, Hugo lo explica así:

Bueno, creo que una de las cosas que me llevó a hacer vídeos en YouTube fue no encontrar referentes, aqui, en Colombia, como que obviamente sí, uno busca en Internet y ve, pues veía en ese momento como testimonios de hombres trans en España, en Estados Unidos, pero de alguna manera uno siente que esa no es su realidad, [...] Yo veía eso y yo decía: ah sí, se puede, pero es allá, no acá, y aquí el único en ese momento, era, era Isaac, y él no subía vídeos constantemente entonces me seguía pareciendo muy, ok ¿se puede hacer aquí o no se puede hacer aquí o cómo estamos en ese sentido en Colombia? Y mi tránsito en ese sentido, siento que lo viví solo (Conversación, 11 de marzo 2019).

La producción de vídeos se ha convertido en un medio de crear espacios que ellos mismos no encontraban para sus preguntas, para sentirse acompañados, para saber que se puede ser trans, que hay otros que han recorrido diferentes caminos, que pueden facilitarle la vida o "aportar un granito de arena" en medio de la invisibilización, el desconocimiento social, político, académico y médico sobre los hombres trans e incluso dentro del propio activismo LGBTI (OVIEDO, 2017).

\section{La espacialidad del código FTM}

Desde los estudios del software, el código se ha entendido como algo oculto e inmaterial que "puede hacer que las cosas funcionen en el mundo de manera autónoma, es decir, [...] actuar sin supervisión o autorización humana"4 (Traducción mía, KITCHIN, \& DODGE, 2011, p. 5). Según lo anterior, yo no era la única que tomaba decisiones, sino que precisamente los algoritmos empezaban a revelar su agencia en la investigación, y posibilitaban ciertos movimientos espaciales en dichas plataformas como el acceso a ciertos cuerpos. Los algoritmos de YouTube como de IG no son neutrales, van delimitando determinadas identidades de género y raciales de manera normativa, hombres trans velludos, musculosos y atractivos (HORAK, 2014), lo cual produce determinadas espacialidades (GIESEKING, 2017).

La suscripción a canales con el código FTM, fue un punto de entrada para poder seguir diversas conexiones (BURREL, 2017) no solo nacionales, sino transnacionales y reconocer el común denominador frente a quienes titulaban sus vídeos FTM y era el papel activo de la Testosterona como un agente clave, espacial y temporalmente en la producción audiovisual como en el tránsito de género de los hombres trans.

Teniendo en cuenta que FTM indica un punto de partida (Female o hembra) y uno de llegada (male o varón), ese camino no es lineal, ni horizontal como

4 "This property of being alive is significant because it means code can make things do work in the world in an autonomous fashion - that is, [...] most significant, act without human oversight or authorization". 
parece reiterarse en las narrativas de hombres trans en YouTube, donde se suele iniciar en Pre-T (Previo a Testosterona), 1 mes en T, 2 meses en T y así sucesivamente. Laura Horak (2014) denomina está fragmentación de la narrativa el "tiempo hormonal" que se ha sedimentado en la estructura audiovisual de dichos canales y permite atraer más aficionados o como expresó Martín "Yo siempre que encontraba mis referentes decía FTM [...] entonces yo lo puse porque sé que mucha gente busca eso" (Conversación, 2 de marzo 2019).

No obstante, los cuerpos se imponen, se afectan, se acomodan, se ajustan según múltiples factores genéticos, hormonales, hereditarios, bioquímicos, alimentarios, etc., que desbordan la voluntad individual de "verse como un hombre". A propósito de por qué es tan importante la testosterona en los tránsitos Martín señaló:

Mi conclusión para esa pregunta en estos momentos sería que el uso de la testosterona hace que tu puedas cumplir con el estereotipo masculino de hombres, o sea si tu no tienes hormonas seguramente no te vas a ver como se ven los hombres, físicamente (Conversación, 2 de marzo 2019).

La relación con la testosterona ha implicado su organización a través de WhatsApp, por ejemplo, debido al desabastecimiento de testosterona que hubo en varios países de América Latina, como Colombia, Uruguay y Chile desde octubre de 2018, más o menos. La información se compartió por las historias de IG. En Colombia se organizaron para asuntos puntuales como solicitar a Bayer AG el medicamento, hasta el derecho de petición al Ministerio de Salud. Este trabajo colectivo no suele ser común y puede ser por las propias maneras en que socialmente es leído un tránsito masculino, en donde ellos mismos reconocen un ascenso social y un mayor apoyo familiar, a diferencia de las mujeres trans, lo que lleva a que realicen sus tránsitos más alejados o poco interesados en el activismo y la organización política (OVIEDO, 2017).

Esta organización reveló los sesgos y estereotipos sobre cómo se debe hacer el tránsito de género, y llevó a que tanto Hugo como Martin se retiraran del chat en bien se hizo el mecanismo jurídico y se iba activando el abastecimiento, después de un largo año. Es decir, entre las propias personas transmasculinas, se reclamaban sobre sus procesos de tránsito y cómo deben ir cumpliendo unas exigencias normativas del "verdadero tránsito", donde la "pasabilidad" se enmarca como el horizonte normativo a seguir (PONTES, \& SILVA, 2017). La testosterona se revela como un agente que también produce competencia y desigualdades entre los cuerpos, según sus formas, proporciones y caracteres secundarios que reafirman determinada identidad.

No es casual que Martin tenga un vídeo llamado "Reglas para ser trans/la construcción de identidad ftm" 5 . Esto da cuenta de cómo la narrativa del tiempo hormonal produce geografías imaginarias sobre cómo deben ser los tránsitos. Si las imágenes son una síntesis de la relación del humano con su

5 Transmutante. (18 abr. 2019). Reglas para ser trans/La construcción de identidad FTM. [Archivo de video]. Recuperado de:

$<$ https://www.youtube.com/watch?v=z_e0pVyXGZI\&t=81s $>$. 


\begin{abstract}
entorno (HIERNAUX, \& LINDÓN, 2012), aquí sería la relación del humano con su primer espacio el cuerpo, es a través de ellas donde también se reafirma estructuralmente el privilegio de los cuerpos cis sobre los trans y presiona a dichos cuerpos a "pasar" como cis para ser validados, lo que se denominaría la cisnormatividad (VERGUEIRO, V. 2015).

Los cuerpos también producen otras estéticas cuando no se expresan los vellos, no se engrosa la voz o la cintura no desaparece. La propia inestabilidad de los cuerpos, produce fisuras y cambios en los espacios de YouTube, que se expresa en las narrativas, en el lenguaje y en el cuerpo de los hombres trans cuando se pintan las uñas o exponen sus frustraciones porque la menstruación no se ha ido o regresó. En términos de la geógrafa feminista Joseli Silva (2009), sería una forma de subvertir, de crear fisuras en el sistema cisheteronormativo, como una manera de abrir las posibilidades de las vidas trans y de hacerse visible en medio de su poder abrumador.

Finalmente, el código FTM es una estrategia de marketing, pero no determina la narrativa, los cuerpos, ni los espacios de la pantalla de Internet que van creando allí los hombres trans, ya sea en YouTube o en IG. Sus cuerpos biológicos se desbordan en esa movilidad e inestabilidad que nos plantea la teoría queer y que claramente se expresa en los espacios y en las sociedades (GIESEKING, 2013). Su lugar de enunciación como activista trans se configura a partir de sus vídeos, y claramente, la Terapia de Reemplazo Hormonal (TRH, en adelante) no simplifica sus tránsitos, pues no son cuerpos desconectados de las políticas sociales, económicas, sanitarias, ni políticas de sus países y transnacionalmente. De ahí, emerge la pregunta por ¿cómo la pandemia de la Covid-19 produce otras espacialidades corporales y discursivas desde las experiencias de los hombres trans en Colombia y México?
\end{abstract}

\title{
Hombres trans encerrados en YouTube
}

La experiencia encarnada de los hombres trans les ha convertido en "expertos", disputándose los espacios de conocimiento que ha tenido la biomedicina desde la producción de la "verdad" sobre la transexualidad (MAS GRAU, 2014; BENTO, 2010). Por ello, su opinión se asume como fuente de conocimiento relevante o como consejos para vivir su experiencia trans de manera más tranquila y menos distante (DAME, 2013). Esto se ha manifestado de maneras particulares en medio de la pandemia por la Covid-19.

Ante la llegada del virus a América Latina, el primero en subir un vídeo fue Hugo a finales de marzo. Días después de determinarse el "simulacro vital" decretado por la alcaldesa Claudia López ${ }^{6}$ para la ciudad de Bogotá y seguido de la medida de la "cuarentena preventiva" desde la presidencia que inicialmente fueron 19 días de aislamiento, según explica Hugo en el vídeo7. Este vídeo inicia una serie que realiza con su esposa Ligia, sobre sus prácticas

\footnotetext{
6 Febres Cordero, D. (20 de marzo 2020). Claudia López presenta el decreto de Simulacro Vital en Bogotá Recuperado de: <https://bogota.gov.co/mi-ciudad/salud/coronavirus/claudialopez-presenta-el-decreto-de-simulacro-vital-en-bogota>.

7 Hugo Martín. (27 de marzo 2020). Capítulo 1: Días de aislamiento - Parlemos. [Archivo de video]. Recuperado de: $<$ https://www.youtube.com/watch?v=7z31FPcOymI\&t=1158s $>$.
} 
y consejos preparándose para el aislamiento, particularmente el espacio desde donde hablan es el comedor, espacio más en común de la casa, no la habitación, su centro de producción audiovisual, como suele ser el espacio desde donde hablan los hombres trans (OVIEDO, 2020).

Seguidamente, la alcaldesa lesbiana decretó la medida del "Pico y género" para la circulación por la ciudad, "hombres" días impares y "mujeres" pares, donde se respetaría "la identidad de género" de las personas, pero abrió las puertas a intensificar las violencias hacia la población trans y no binarie como señaló la Fundación GAAT (Grupo de Acción y Apoyo a Personas Trans). Al tomar una medida binaria y cisnormativa le daba la potestad a lxs policías, vigilantes, vendedores y ciudadanía de afinar su ojo generizador (SERANO, 2009) para definir quién podía estar en la calle, quién podía mercar y quiénes no, entonces ¿cuándo pueden salir las personas no binarias, marimachas, trans que no nos vemos como "mujeres y hombres", o quiénes no han cambiado su componente de sexo en los documentos de identificación? Ante las violencias desatadas por esta medida, Martin hizo su denuncia en YouTube, por el abuso policial histórico que va desde la humillación, golpes, abuso sexual hasta el asesinato, al que ha llegado la policía, y recuerda el caso de Carlos Torres en la UPJ de Bogotá en el $2015^{8}$.

Por ello, Joseph ${ }^{9}$ no pudo comprar sus alimentos porque no le respetaron su identidad de género masculina en un supermercado. Él tuvo que dar explicaciones sobre su identidad, incluso hay vídeos donde las personas trans afirman que están en TRH como si fuera la llave de entrada al mundo cisnormativo, pero a Joseph al final, en medio de burlas de otros hombres cis, lo expulsaron del establecimiento. Salió, activó la cámara de su celular y contó lo que había sucedido, y así pudo ser compartido por organizaciones como la @redcomunitariatrans y Martin en su canal. Aunque Hugo puede "pasar" como hombre cis, reconoce el miedo, pues se siente ligado colectivamente como trans, lo cual no es inocente frente a sus medidas de seguridad.

Ace Eckstein (2016) señala la importancia no solo de los canales individuales, sino de los "contrapúblicos" que producen dichos canales, por eso las preguntas y cuestionamientos del propio tránsito son clave, de figuras que se vuelven referentes de los tránsitos por su expertness, su habilidad para persuadir, aconsejar y motivar (DAME, 2013). Asumir el rol de denunciante produce cierto tipo de espectadores, que en su rol como trans, aliadx y/o ciudadanx puede accionar o apoyar procesos que protejan sus propias vidas o de quienes disentimos de la cisheteronormatividad.

Muchos de sus cuestionamientos van dirigidos hacia la población trans, que es su público principal, por ello Carlos hace un vídeo sobre la cuarentena en el closet $^{10}$ donde interpela a aquellos hombres que no les reconocen como trans o

8 Londoño Á., Julio C. (11 de diciembre 2015). La muerte de Paula Torres en una UPJ, ¿suicidio o abuso policial? Vice. Recuperado de: $<$ https://www.vice.com/es_co/article/nnpxjg/paula-torres-suicidio-o-abuso-policial $>$.

9 Redcomunitariatrans \#NoAlPicoYGenero (15 de abril). Recuperado de: $<$ https://www.instagram.com/p/B_A6jwYp64J/>.

10 El tren de Carlos (22 de abril 2020). Cuarentena en el closet [Archivo de video] Recuperado de: $<$ https://www.youtube.com/watch?v=DF6AHcA6Zps\&t=248s $>$. 
quiénes no lo han compartido con su familia. De manera jocosa y empática les resalta que van a cumplir 4 semanas encerrados, escuchando el pronombre y el nombre que no les gusta, y entendiendo que puede ser por algún motivo económico, les pregunta: “¿Bajo qué costo estás esperando, 336 horas y las que te faltan, de verdad vale la pena?", pone títulos sobre su imagen de las horas que llevan "soportando estar en casa". Por ello les invita a que hablen con su familia, para que el encierro sea la posibilidad de salir del clóset, pero también de concentrar su energía en algo más grande que está pasando en el mundo como la pandemia y que de ello no resulten suicidios como un hecho reiterado que me había señalado Carlos en nuestras conversaciones.

Carlos se ha propuesto siempre tener una actitud amable y alegre para su público, pero también hay circunstancias en las que no es posible y Martin lanza una crítica frente a cómo se resaltan determinadas emociones en las redes sociales: la felicidad, satisfacción y éxito como valores que según él no son reales. Ahí emerge la pregunta por ¿qué espacialidades emocionales producen los hombres trans en YouTube? Precisamente hizo un vídeo con un título que invita a saber qué está pasando con él y cuáles pueden ser las condiciones para un hombre trans en "cuarentena"11. Su expresión facial expresa tristeza e incertidumbre, porque previo a la cuarentena le suspendieron la TRH, llevaba dos meses sin aplicarse su dosis y tenía citas con especialistas que por las condiciones del virus le daba miedo ir a un hospital y no había disponibilidad, tampoco. Por ello le dijo a su público:

Yo muchas veces les he hablado de la importancia de llevar el tratamiento hormonal con compañía de un especialista, de un médico, porque yo puedo inyectarme testosterona como a mí se me dé la gana, cuando quiera, porque sé que muchxs lo han hecho, sé que muchxs lo están haciendo, pero les ruego (Junta sus manos en posición de oración) que paren de hacerlo, si lo están haciendo (YouTube, 23 de abril 2020).

Expresar la angustia, las incomodidades o frustraciones también debe tener cabida en estos espacios, afirma Martin, pero a la luz de reflexionar si el proceso de tránsito se puede restringir a ir al médico e inyectarse sus dosis de testosterona. Él coincide con Carlos acerca de tener una mirada más amplia, sin desconocer sus procesos individuales, y aprender algo de sí mismos en medio del encierro y del aislamiento físico. Lo que cuestiona de nuevo el lugar privilegiado de la TRH como el medio para legitimar los tránsitos.

A su vez, las cámaras son dispositivos clave para contar otras historias además de las mainstream que en los últimos años salen en la televisión y el cine (ECKSTEIN, 2016), pero también producen el género al volverse el espejo para revelarse, la creación artística, el registro de sus propias experiencias y pensamientos (RAUN, 2015). Lo que se puede señalar en tiempos de pandemia, es cómo las cámaras y los canales de YouTube se han convertido en dispositivos de defensa, denuncia y difusión de información ante

11 Transmutante. (23 abr. 2020). Cuarentena Para Chicos Trans Ftm/ Me Quitaron Las Hormonas. [Archivo de video] $<$ https://www.youtube.com/watch?v=0VZFI8FZ7PE\&t=574s $>$. 


\begin{abstract}
la vulneración de los DDHH de la población trans y no binarie. Ya no es solo el espacio para la historia personalísima y espectacular (HORAK, 2014) o el espacio del "narcisimo saludable" (RAUN, 2014), sino que se ha ampliado frente a otras necesidades, incluso la de exponer la propia frustración y vulnerabilidad del habitarse siendo trans.
\end{abstract}

\title{
Apuntes Finales
}

Para finalizar, quiero sugerir cómo los espacios digitales se han ido configurando en geografías de encuentro en términos de Gill Valentine (2008), que no se da en los espacios urbanos de la calle o el parque, sino cómo pensar esas geografías del encuentro en los espacios digitales donde escuchar otras voces, ver otras imágenes de cuerpos que no son musculosos, ni barbados y de hombres que deben interrumpir su TRH por cuestiones de salud, ayuda a disminuir la ansiedad, la soledad, la distancia y el miedo de habitar sus cuerpos y sus tránsitos ahora más que antes. Es fundamental, abrir espacios donde las personas trans y no binaries podamos encontrar referencias de cómo vivir encerrados, de cómo enfrentar a nuestra familia, y seguir encontrando maneras en que los espacios que habitamos: los cuerpos, las habitaciones, la sala y nuestras redes sociales permitan también ser espacios seguros para transitar nuestros géneros, deseos y corporalidades.

La pandemia de la Covid-19 aun es un campo abierto de exploración, precisamente porque las desigualdades sociales se han intensificado, de ahí la importancia de los youtubers como voceros y difusores de las denuncias y vulneraciones de DDHH de las personas trans en sus respectivos contextos geopolíticos. Precisamente, el virus ha evidenciado la relevancia de los espacios de la Internet como configurador de geografías de encuentro para lo laboral, emocional, deportivo, comercial, espiritual, etc.; por lo tanto, es clave seguir las conexiones y los rastros de los hombres trans como de las disidencias sexuales y de género que también habitan la Internet y que buscan abrir espacios, aunque impere la incertidumbre, las violencias y el miedo.

\section{Bibliografía}

BENTO, Berenice. La producción del cuerpo dimórfico: transexualidad e historia. Anuario de Hojas de Warmi, n. 15, p. 1 - 19, 2010.

BURRELL, Jenna. The Fieldsite As A Network A Strategy for Locating Ethnographic Research. En: HJORTH, L Larissa.; HORST, H Heather; GALLOWAY, Anne; BELL, G Genevieve. (Eds.). The routledge companion to digital ethnography. New York: Routledge, 2017, p. 51 - 60.

CURIEL, Ochy. La nación heterosexual Análisis del discurso jurídico y el régimen heterosexual desde la antropología de la dominación. Bogotá: Brecha Lésbica y en la frontera, 2013.

DAME, Avery P. I'm your hero? Like me? The role of 'expert' in the trans male vlog. Journal of Language and Sexuality, v. 2, n. 1, p. 40 - 69, 2013. 
Espacialidades de Hombres Trans Youtubers: Acercamiento a sus Condiciones en la Pandemia del Covid-19

ECKSTEIN, Ace Jordan. Documenting Transition, Transforming Gender: the Worldmaking Work of Trans Men on Youtube. 2016. Tesis (Master of Arts) - University of Colorado, Boulder.

KITCHIN, R.; DODGE, M. Code/space: software and everyday life. London, MIT Press, 2011.

HIERNAUX, Daniel; LINDÓN, Alicia. Renovadas intersecciones: la espacialidad y los imaginarios. En: HIERNAUX, Daniel; LINDÓN, Alicia (Dirs.). Geografías de lo imaginario. México: Anthropos Editorial, 2012, p. 9 $-28$.

HORAK, Laura. Trans on YouTube Intimacy, Visibility, Temporality. TSQ: Transgender Studies Quarterly, v. 1, n. 4, p. 572 - 585, 2014.

KELLERMAN, A. Geographic Interpretations of the Internet. Haifa: Springer Briefs in Geography, 2016.

MAS GRAU, J. Subjetividades y cuerpos gestionados: un estudio sobre la patologización y medicalización del transgénero. 2014. Tesis doctoral (Estudis Avançats en Antropologia Social)- Universitat de Barcelona, Barcelona.

ORNAT, Marcio Jose. Espaços interditos e a constituição das identidades travestis através da prostituição no Sul do Brasil. Revista Latino-americana de Geografia e Gênero, v. 3, n. 1, p. 54 - 73, 2012.

OVIEDO, Laura. Cuando me levante, quiero ser un niño. Concepción corporal y construcción discursiva de hombres trans en las ciudades de Medellín y Bogotá D.C. 2017. Monografía (Antropología)- Universidad de Antioquia, Medellín.

OVIEDO, Laura. Female Tube Male: Geografías de hombres trans para existir en Internet. 2020. Tesis (Maestría en Estudios Socioespaciales)Universidad de Antioquia, Medellín.

PRADA, Nancy; TORRES, Fernando; SÁNCHEZ, Marcela; RAMÍREZ, Fidel Mauricio; SUÁREZ, Paola. Todo debate es ideológico. Reflexiones acerca de la 'ideología de género'. Polisemia, n. 22, p. 115 - 125, 2016.

PONTES, Júlia Clara de; SILVA, Cristiane Gonçalves da. Cisnormatividade e passabilidade: deslocamentos e diferenças nas narrativas de pessoas trans. Revista Periódicus, n. 8, v. 1. p. 396 - 417, 2018.

RODRÍGUEZ, Manuel. La ideología de género como exceso. Pánico moral y decisión ética en la política colombiana. Sexualidad, Salud y Sociedad Revista Latinoamericana, n. 27, p. 128 - 148, 2017. 
SERANO, Julia. Whipping Girl. A Transsexual Woman on Sexism and The Scapegoating of Femininity. Nueva York: Seal Press, 2007.

SILVA, Joseli. María. Ausências e silêncios do discurso geográfico brasileiro. En: SILVA, Joseli María. Geografias subversivas. discursos sobre espaço, gênero e sexualidades. Ponta Grossa: Todapalavra Editora, 2009, p. 55 - 92.

VALENTINE, Gil; HOLLOWAY, Sarah. Cyberkids? Exploring Children's Identities and Social Networks in On-line and Off-line. Worlds Annals of the Association of American Geographers, v. 92, n. 2, p. 302 - 319, 2002.

VERGUEIRO, Viviane. Por inflexões decoloniais de corpos e identidades de gênero inconformes: uma análise autoetnográfica da cisgeneridade como normatividade. 2015. Tesis (Mestrado en Programa Multidisciplinar de Pós-Graduação em Cultura e Sociedade. Universidade Federal Da Bahia, Salvador. 